\title{
Comparison of Phenolic Content of Easily Removed Pellicle of Japanese Chestnut 'Porotan' with Other Japanese and Chinese Chestnut Cultivars
}

\author{
Akihiko Sato***, Keiichi Tanaka, Norio Takada, Yutaka Sawamura*** \\ and Toshio Hirabayashi \\ National Institute of Fruit Tree Science, National Agriculture and Food Research Organization, Tsukuba 305-8605, Japan
}

The amount of phenolic compound contained in the chestnut pellicle determines the degree of adhesiveness between the pellicle and kernel. The difficulty involved in pellicle removal in Japanese chestnut results from the accumulation of a large amount of phenolic compound in the pellicle. A new Japanese chestnut cultivar, 'Porotan', has a pellicle that is easily removed, like Chinese chestnut. In this study, the phenolic content of 'Porotan' pellicles was quantified and compared to those of Japanese ('Kunimi' and 'Tsukuba'), Chinese ('Houji 360' and 'Miyazakishinaguri'), and interspecific hybrid ('Riheiguri') chestnuts. Even though total phenolic content in 'Porotan' was highest among the cultivars measured, the 'Porotan' pellicle could be removed quickly. On the other hand, the phenolic content in a water-soluble extract, which shows the amount of phenolic compound accumulated on the inner surface of the pellicle, was low for 'Porotan' comparable to Chinese chestnut. Similar to total phenolic content, the phenolic content in an alcohol-soluble extract of 'Porotan', which shows the amount of phenolic compound accumulated in pellicle tissue, was highest among the cultivars. These results showed that the accumulation of phenolic compound on the inner surface of the 'Porotan' pellicle was low despite a large amount of phenolic compound in the pellicle tissue, and that the low accumulation of phenolics on the inner surface of the pellicle resulted in weak adhesion between the pellicle and kernel in 'Porotan'.

Key Words: chestnut, pellicle removal, phenolic content, 'Porotan'.

\section{Introduction}

Japanese chestnut (Castanea crenata Sieb. et Zucc.) has been produced in Japan since before written history and now accounts for a total annual production of over 20,000 t (Ministry of Agriculture, Forestry and Fisheries, 2009). Japanese chestnut has generally large and highquality nuts, but its pellicle is more difficult to remove from the kernel than that of Chinese chestnut (Castanea mollissima Bl.) (Kikuchi, 1948; Miller et al., 1996). The national production of Japanese chestnut has been gradually decreasing, by about $50 \%$ in the past two

Received; July 31, 2009. Accepted; February 22, 2010.

This paper was presented at the 2009 Spring Meeting of the Japanese Society for Horticultural Science.

* Corresponding author (E-mail: satoaki@affrc.go.jp).

** Present address: Grape and Persimmon Research Station, National Institute of Fruit Tree Science, National Agriculture and Food Research Organization, Akitsu, Higashihiroshima 7392494, Japan.

*** Present address: Headquarters, National Agriculture and Food Research Organization, Tsukuba 305-8517, Japan. decades. One probable reason for the decrease in Japanese chestnut production in Japan is the laborious and costly pellicle removal process. While the national production of Japanese chestnut is decreasing, large quantities of Japanese chestnut kernels after pellicle removal have been imported from China and Korea, where the cost of removing the pellicle is lower than in Japan.

A new Japanese chestnut cultivar, 'Porotan', was released by the National Institute of Fruit Tree Science in 2006. 'Porotan' has a pellicle that is easily removed although it originated from a cross of pure Japanese chestnut cultivars and selections (Hirabayashi et al., 2007). 'Porotan' gradually increases in chestnut-growing areas in Japan because it has an easily removed pellicle and excellent nut quality; however, the reason for its easy pellicle removal is not clear.

The mechanism of pellicle adhesiveness in chestnut has been clarified in a series of studies (Tanaka and Kotobuki, 1992a, 1992b, 1998a, 1998b; Tanaka et al., 1981). According to these studies, the difference in the ease of pellicle removal is determined by the amount of 
phenolic compound accumulated in the pellicle (Tanaka et al., 1981), and the phenolic content is higher in Japanese than Chinese chestnut. Hara et al. (1995) also observed that pellicle cells in Japanese chestnut were crushed during nut growth, whereas those in Chinese chestnut degraded slowly. Moreover, Tanaka and Kotobuki (1998a, 1998b) revealed that the phenolics was mainly composed of $(+)$-catechin, its polymer, and gallic acid, and that the phenolic compound substance associated with adhesion was a polymer containing (+)catechin, named "castahesion". Changes in phenolic compounds during the stages of nut development have been reported by Tanaka and Kotobiki (1992a). According to their report, in the immature nut stage, phenolic compounds have not accumulated in the pellicle, so the pellicle is easily removed from the kernel. As maturity progresses, phenolic compound accumulates rapidly in tannin cell-like cells of pellicle. At nut maturing stage, a large amount of phenolic compound accumulates not only in pellicle tissue but also on inner surface of pellicle. After nuts drop, adhesion between kernel and pellicle completes immediately (Tanaka and Kotobuki, 1992a).

Because 'Porotan' was derived from a cross between Japanese chestnuts, the mechanism of the ease of pellicle removal has been unknown. Comparing phenolic content in the pellicle of 'Porotan' with that of Chinese chestnut cultivars would provide important information on the mechanism and genetics of the ease of pellicle removal. Therefore, the objectives of this study were to quantify the amount of phenolic compound in 'Porotan' pellicles and to compare this amount to those of other Japanese and Chinese chestnut cultivars.

\section{Materials and Methods}

\section{Plant materials}

Six cultivars of three Japanese chestnuts ('Porotan', 'Kunimi', and 'Tsukuba'), two Chinese chestnuts ('Houji 360 ' and 'Miyazakishinaguri'), and an interspecific hybrid ('Riheiguri') were used in this study (Table 1). The parentage of 'Riheiguri' is unknown, but it has been considered an interspecific hybrid of Japanese chestnut and Chinese chestnut (Kotobuki, 1996). Evaluation of pellicle removal time and measurement of phenolic content were conducted in the 2007 season. Before evaluation and measurement, the ease of pellicle removal of deep-fried nuts (HOP method, Shoda et al., 2006) or roasted nuts of the cultivars used in this study was confirmed (Table 1). Immature nuts were taken from burs just before opening on a tree of each cultivar. At this stage, the amount of phenolic compound rapidly increases in the pellicle and starts to accumulate on its inner surface (Tanaka and Kotobuki, 1998b; Tanaka et al., 1981). Nut samples were taken on August 31 from 'Porotan' and 'Kunimi,' September 14 from 'Riheiguri' and 'Tsukuba', and September 28 from 'Houji 360' and 'Miyazakishinaguri'.

\section{Evaluation of pellicle removal time}

Fifteen immature nuts were used to evaluate the pellicle removal time. Open pollinated nuts taken from burs of each cultivar were weighed immediately. After the nutshell was removed, the pellicle was removed using a fruit knife and the pellicle removal time was measured. The pellicle removal time was defined as the time needed to remove the pellicle from the kernel without damaging the kernel. Pellicles removed from five nuts of each cultivar were weighed and immediately frozen in liquid nitrogen. The frozen pellicles were maintained at $-80^{\circ} \mathrm{C}$ until the measurement of phenolic content.

\section{Measurement of phenolic and flavonoid contents}

To measure phenolic content, $5 \mathrm{~g}$ of frozen pellicles from each cultivar was placed in $40 \mathrm{ml}$ distilled water in a beaker and stirred slowly at room temperature. After the water had reached room temperature, the sample was centrifuged at $1534 \times \mathrm{g}$ for $10 \mathrm{~min}$ and the supernatant decanted. The precipitate was washed with distilled water and centrifuged at $1534 \times \mathrm{g}$ twice for $10 \mathrm{~min}$ each. Three supernatants were mixed and made up to $100 \mathrm{ml}$ with water. The extract was used to measure phenolic content in a water-soluble extract (WS phenolic content), indicating the content of phenolic compound accumulated on inner surface of pellicle. The precipitate was homogenized with $40 \mathrm{ml}$ of $80 \%$ methanol $(\mathrm{MeOH})$, and kept at $80^{\circ} \mathrm{C}$ for $15 \mathrm{~min}$. The homogenate was then centrifuged at $2963 \times \mathrm{g}$ for $10 \mathrm{~min}$ and supernatant decanted. The pellet was washed with fresh $80 \% \mathrm{MeOH}$ and centrifuged twice. Three supernatants were mixed and made up to $100 \mathrm{ml}$ with the same solvent. The extract

Table 1. Cultivar, species, and ease of pellicle removal using deep-fried or roasted nuts.

\begin{tabular}{lcc}
\hline \hline Cultivar & Species & $\begin{array}{c}\text { Ease of pellicle removal of } \\
\text { deep-fried or roasted nuts }\end{array}$ \\
\hline 'Porotan' & C.crenata & Easy \\
'Kunimi' & C.crenata & Difficult \\
'Tsukuba' & C.crenata & Difficult \\
'Riheiguri' & Probable interspecific hybrid between C. crenata and C. mollissima & Intermediate \\
'Houji 360' & C. mollissima & Easy \\
'Miyazakishinaguri' & C.mollissima & Easy \\
\hline
\end{tabular}

${ }^{\mathrm{z}}$ Pellicle removal test using deep-fried nuts was according to the method reported by Shoda et al. (2006). 
was used to measure phenolic content in an alcoholsoluble extract (AS phenolic content), indicating the content of phenolic compound accumulated in pellicle tissue. WS and AS phenolic contents were measured using the Folin-Denis method with (+)-catechin as a standard at $700 \mathrm{~nm}$ with a colorimeter, according to Tanaka et al. (1981). The measurements were repeated three times, and the data were averaged for each extracts.

After WS and AS had been extracted, each pellet consisted of alcohol-insoluble solids (AIS) of the pellicle, which were vacuum-dried. Five hundred milligrams of dried pellicle AIS was placed in a test tube containing $20 \mathrm{ml}$ distilled water and $0.125 \mathrm{~g}$ sodium chlorite $\left(\mathrm{NaClO}_{2}\right)$ in a water bath maintained at $60^{\circ} \mathrm{C}$. Then, $0.3 \mathrm{ml}$ of acetic acid was added. At $30 \mathrm{~min}, 2 \mathrm{~h}$, and $3 \mathrm{~h}$ after the addition of acetic acid, $0.125 \mathrm{~g} \mathrm{NaClO}_{2}$ and $0.3 \mathrm{ml}$ acetic acid were also added. The reaction was stopped after another $3 \mathrm{~h}$. The solid residue was washed and centrifuged with $80 \% \mathrm{MeOH}$ at $1534 \times \mathrm{g}$ three times for $10 \mathrm{~min}$ each time. Then, the residue was vacuumdried and weighed. Because phenolic compound is decomposed oxidatively by sodium chlorite and is solubilized in water, the amount of phenolic compound in the AIS was calculated as the difference between AIS weights before and after sodium chlorite treatment (Tanaka and Kotobuki, 1998b). Phenolic content in AIS (AIS phenolic content) was estimated for three pellets taken from 15 nuts (each pellet was taken from 5 nuts), with the exception of 'Houji 360' (two pellets). Total phenolic content was calculated as the sum of WS, AS, and AIS phenolic contents.

Flavonoids in the pellicle were mainly composed of (+)-catechin and its polymer, because monophenolic substances in WS of the chestnut pellicle were composed mainly of (+)-catechin and gallic acid (Tanaka and Kotobuki, 1998b). Flavonoid contents in WS and AS were measured using the vanillin- $\mathrm{H}_{2} \mathrm{SO}_{4}$ method (Nakabayashi, 1967) with (+)-catechin as the standard. The measurements were repeated three times, and data were averaged for each extract.

\section{Data analysis}

Data were subjected to one-way analysis of variance and Tukey's honestly significant difference (HSD) test with the exception of pellicle weight. Data on pellicle weight were subjected to Wilcoxon's test, because uniformity of variance was rejected at $P=0.05$.

\section{Results}

Nut weights ranged from 16.9 to $33.3 \mathrm{~g}$, depending on the cultivar (Table 2). Nut weight of 'Porotan' was $24.3 \mathrm{~g}$, significantly larger than 'Houji 360' and 'Miyazakishinaguri' but smaller than 'Riheiguri' and 'Kunimi'. Pellicle weights ranged from 1.20 to $4.13 \mathrm{~g}$ and were approximately three times larger in 'Kunimi' than in 'Houji 360' and 'Miyazakishinaguri'. Pellicle weights were closely related to nut weights.

Pellicle removing times were $916 \mathrm{~s}, 774 \mathrm{~s}, 300 \mathrm{~s}, 139 \mathrm{~s}$, $81 \mathrm{~s}$, and $81 \mathrm{~s}$ for 'Tsukuba', 'Kunimi', 'Riheiguri', 'Porotan', 'Houji 360', and 'Miyazakishinaguri', respectively. The pellicle removal time for 'Porotan' was significantly shorter than for 'Kunimi' and 'Tsukuba' and similar to the Chinese chestnut cultivars. This trend in the pellicle removal time was similar to the result using deep-fried or roasted nuts tested previously (Table 1).

Total phenolic contents ranged from 136 to $209 \mathrm{mg} \cdot \mathrm{g}^{-1} \mathrm{FW}$, depending on the cultivar (Table 3). Total phenolic content in 'Porotan' was as high as in other Japanese chestnut cultivars, but the contents in Chinese chestnut cultivars were significantly lower than in Japanese chestnut cultivars. WS phenolic contents ranged from 24 to $58 \mathrm{mg} \cdot \mathrm{g}^{-1} \mathrm{FW}$. WS phenolic content in 'Porotan' was significantly lower than in 'Tsukuba' and 'Kunimi' and was comparable to 'Riheiguri', 'Houji 360', and 'Miyazakishinaguri'. AS phenolic contents ranged from 53 to $133 \mathrm{mg} \cdot \mathrm{g}^{-1} \mathrm{FW}$. AS phenolic content in 'Porotan' was highest among the cultivars tested in spite of its low WS phenolic content. Total, WS, and AS phenolic contents in 'Houji 360' and 'Miyazakishinaguri' were low, whereas those in 'Kunimi' and 'Tsukuba' were high. Thus, total phenolic contents were proportional to WS and AS phenolic contents, except in 'Porotan'. In contrast, the proportions of AIS phenolic contents to total phenolic contents were generally higher in Chinese chestnut cultivars (43-44\%) than in Japanese chestnut cultivars (20-23\%); however, the differences among cultivars were not large compared

Table 2. Nut weight, pellicle weight, and pellicle removal time in 6 cultivars ${ }^{2}$.

\begin{tabular}{lccc}
\hline \hline Cultivar & Nut weight $^{\mathrm{y}}(\mathrm{g})$ & Pellicle weight $^{\mathrm{x}}(\mathrm{g})$ & Pellicle removal time $^{\mathrm{y}}(\mathrm{s})$ \\
\hline 'Porotan' & $24.3 \mathrm{c}$ & $2.48 \mathrm{c}$ & $139 \mathrm{c}$ \\
'Kunimi' & $33.3 \mathrm{a}$ & $4.13 \mathrm{a}$ & $774 \mathrm{a}$ \\
'Tsukuba' & $27.0 \mathrm{bc}$ & $2.81 \mathrm{bc}$ & $916 \mathrm{a}$ \\
'Riheiguri' & $30.1 \mathrm{ab}$ & $2.99 \mathrm{~b}$ & $300 \mathrm{~b}$ \\
'Houji 360' & $19.9 \mathrm{~d}$ & $1.40 \mathrm{~d}$ & $81 \mathrm{c}$ \\
'Miyazakishinaguri' & $16.9 \mathrm{e}$ & $1.20 \mathrm{e}$ & $81 \mathrm{c}$ \\
\hline
\end{tabular}

${ }^{z}$ Nuts were sampled just before the burs opened in each cultivar.

y Mean separation within the same columns by Tukey's HSD test, $P<0.05$, after log-transformation.

${ }^{x}$ Mean separation within the same columns by Wilcoxon's test, $P<0.05$. 
Table 3. Phenolic and flavonoid contents of pellicle surface and pellicle tissue in 6 cultivars $^{\mathrm{z}}$.

\begin{tabular}{|c|c|c|c|c|c|c|}
\hline \multirow{2}{*}{ Cultivar } & \multicolumn{4}{|c|}{ Phenolics $\left(\mathrm{mg} \cdot \mathrm{g}^{-1} \mathrm{FW}\right)$} & \multicolumn{2}{|c|}{ Flavonoids $\left(\mathrm{mg} \cdot \mathrm{g}^{-1} \mathrm{FW}\right)$} \\
\hline & Total & $\mathrm{WS}^{\mathrm{y}}$ & $\mathrm{AS}^{\mathrm{x}}$ & $\mathrm{AIS}^{\mathrm{w}}$ & $\mathrm{WS}^{\mathrm{y}}$ & $\mathrm{AS}^{\mathrm{x}}$ \\
\hline 'Porotan' & $209 \mathrm{a}^{\mathrm{v}}$ & $27 \mathrm{~b}$ & $133 \mathrm{a}$ & 49 bcd & $13 \mathrm{~b}$ & $54 \mathrm{a}$ \\
\hline ‘Kunimi’ & $198 \mathrm{a}$ & $49 \mathrm{a}$ & $111 \mathrm{~b}$ & $39 \mathrm{~d}$ & $26 \mathrm{a}$ & $50 \mathrm{ab}$ \\
\hline ‘Tsukuba’ & $202 \mathrm{a}$ & 58 a & $98 \mathrm{bc}$ & $46 \mathrm{~cd}$ & $30 \mathrm{a}$ & 42 abc \\
\hline 'Riheiguri' & $161 \mathrm{~b}$ & $28 \mathrm{~b}$ & $81 \mathrm{c}$ & $52 \mathrm{abc}$ & $12 \mathrm{~b}$ & $39 \mathrm{bcd}$ \\
\hline 'Houji 360’' & $147 \mathrm{bc}$ & $24 \mathrm{~b}$ & $57 \mathrm{~d}$ & $64 \mathrm{a}$ & $12 \mathrm{~b}$ & $33 \mathrm{~cd}$ \\
\hline 'Miyazakishinaguri' & $136 \mathrm{c}$ & $24 \mathrm{~b}$ & $53 \mathrm{~d}$ & $59 \mathrm{ab}$ & $10 \mathrm{~b}$ & $29 \mathrm{~d}$ \\
\hline
\end{tabular}

${ }^{\mathrm{z}}$ Nuts were sampled just before the burs opened in each cultivar.

y Water-soluble extract on surface of pellicle.

x Alcohol-soluble extract of pellicle tissue.

${ }^{w}$ Alcohol-insoluble solids of pellicle tissue.

v Mean separation within the same columns by Tukey's HSD test, $P<0.05$.

to WS and AS phenolic contents.

WS flavonoid content in 'Porotan' was significantly lower than in 'Tsukuba' and 'Kunimi', whereas AS flavonoid content in 'Porotan' was highest among the cultivars (Table 3 ). These trends were similar to the phenolic contents measured using the Folin-Denis method. The proportions of flavonoids to phenolics in 'Porotan' were $48 \%$ for WS and $41 \%$ for AS, respectively; these proportions were almost identical to other cultivars.

Spearman's rank correlation between total phenol content and pellicle removal time was $r_{s}=0.64$, which was not significant; however, it was significant when 'Porotan' was excluded $\left(r_{S}=0.97^{* *}\right)$ (Table 4$)$. The rank correlation between WS phenolic content and pellicle removal time was high in all six cultivars and in the five cultivars excluding 'Porotan' $\left(r_{S}=1.00^{* *}\right)$. The value of rank correlation between AS phenolic content and pellicle removal time was not high $\left(r_{s}=0.58\right)$; however, it rose when 'Porotan' $\left(r_{s}=0.87\right)$ was excluded. Thus, the rank correlations between the pellicle removal time and total and AS phenolic contents tended to increase when 'Porotan' was excluded. Unlike other extracts, AIS phenolic contents were negatively proportional to pellicle removal times.

\section{Discussion}

In this study, pellicles were sampled just before bur opening, when phenolic compounds had rapidly accumulated in the pellicle but had not completely moved to the pellicle surface (Tanaka and Kotobuki, 1992a). WS phenolic content, the phenolic compound on the surface of pellicles, directly contributed to adhesion of the pellicle and kernel at this stage. This explains the high correlation between WS phenolic content and pellicle removal time in this study.

WS phenolic content was low in 'Porotan' and was comparable to Chinese chestnut cultivars. Low WS phenolic content in 'Poratan' was closely associated with the ease of pellicle removal, as it was in Chinese chestnut cultivars. On the other hand, previous studies suggest that the measurement of AS phenolic content is
Table 4. Spearman's rank correlation between pellicle removal time and phenolic contents of pellicle surface and pellicle tissue in 6 cultivars or 5 cultivars excluding 'Porotan'z.

\begin{tabular}{|c|c|}
\hline Phenolic Extract & Spearman's rank correlation \\
\hline \multicolumn{2}{|l|}{ Total } \\
\hline 6 cultivars & $0.64^{\mathrm{NS} y}$ \\
\hline 5 cultivars excluded 'Porotan' & $0.97 * *$ \\
\hline \multicolumn{2}{|l|}{ WS $^{x}$} \\
\hline 6 cultivars & $1.00 * *$ \\
\hline 5 cultivars excluded 'Porotan' & $1.00 * *$ \\
\hline \multicolumn{2}{|l|}{$\mathrm{AS}^{\mathrm{w}}$} \\
\hline 6 cultivars & $0.58^{\mathrm{NS}}$ \\
\hline 5 cultivars excluded 'Porotan' & $0.87^{\mathrm{NS}}$ \\
\hline \multicolumn{2}{|l|}{ AIS $^{v}$} \\
\hline 6 cultivars & $-0.87 * *$ \\
\hline 5 cultivars excluded 'Porotan' & $-0.87^{\mathrm{NS}}$ \\
\hline
\end{tabular}

${ }^{z}$ Nuts were sampled just before the burs opened in each cultivar.

y NS, ** Non-significant or significant at $P<0.01$.

${ }^{x}$ Water-soluble extract on surface of pellicle.

${ }^{w}$ Alcohol-soluble extract of pellicle tissue.

$\checkmark$ Alcohol-insoluble solids of pellicle tissue.

proportional to the total and WS phenolic contents (Tanaka and Kotobuki, 1992a, 1998b; Tanaka et al., 1981). In this study, as suggested by the previous studies, AS phenolic content in five cultivars excluding 'Porotan' was proportional to total and WS phenolic contents, that is, high for Japanese chestnut cultivars and low for Chinese chestnut cultivars; however, WS phenolic content was low for 'Porotan' in spite of the high contents of both total and AS. This result suggests that phenolic compounds in 'Porotan' do not move easily from inside pellicle tissue to the inner surface, which likely explains why the pellicle can be removed easily despite the high total phenolic content.

As mentioned above, flavonoids in the chestnut pellicle were mainly composed of (+)-catechin and its polymer (Tanaka and Kotobuki, 1998b). In this study, the proportions of flavonoids to phenols in both WS and AS extracts in 'Porotan' were not low compared to other 
cultivars, suggesting that the ease of pellicle removal in 'Porotan' was not due to a low catechin content. Thus, unknown factors may control the ease of pellicle removal in 'Porotan'. In further studies, the imbalance between WS and AS phenolic contents in 'Porotan' should be the focus. So far, we have observed that the pellicle in pest- or fungus-affected 'Porotan' nuts was difficult to remove even after being heated (unpublished data), indicating strong adhesion when pellicle cells are broken. This phenomenon suggests that the ease of 'Porotan' pellicle removal is supported by a mechanism that keeps a large amount of phenolics in the pellicle cells. The strength of the pellicle cell wall, as suggested by Hara et al. (1995), and/or the molecular size of phenolics in the vacuole of pellicle cells may control this mechanism.

AIS phenolic contents were not high, ranging from 20 to $44 \%$ of the total phenolic contents. Moreover, AIS phenolic content was negatively correlated with the pellicle removal time, probably because of the high AIS content in Chinese chestnut cultivars. According to Tanaka and Kotobuki (1992a, 1998b), AS phenolics change to WS phenolics after the nuts fall, and then WS phenolics rapidly change to AIS phenolics. Complete adhesion between the pellicle and kernel is induced by the change to AIS phenolics, that is, polymerization; therefore, the small proportion of AIS phenolic content and the negative correlation between the pellicle removal time and AIS phenolic content in this study suggest that the contribution of AIS phenolics to adhesion is likely to be small in the immature nut stage, as indicated by Tanaka and Kotobuki (1992a, 1998b).

In conclusion, the ease of pellicle removal in 'Porotan' was explained by the low phenolic content on the inner surface of the pellicle; however, the accumulation of phenolic compounds in pellicle tissue of 'Porotan' was high, comparable to those of other Japanese chestnut cultivars. Because the reason for the imbalance in the accumulation of phenolic compounds between pellicle tissue and the inner surface of the pellicle in 'Porotan' is not clear, further studies such as analyses of the physical and/or chemical properties of the pellicle, and determination of the molecular size of phenolics will be required. The cultivation of Chinese chestnut in Japan was initiated in the late 19th century (Kotobuki, 1994). In spite of great efforts, commercial cultivation did not succeed because of the difficulty of pellicle removal when Chinese chestnut was pollinated with Japanese chestnut (Osaki and Sasou, 1942). The ease of pellicle removal in 'Porotan', on the other hand, did not fluctuate depending on the pollinizer (Takada et al., 2009). Further studies are also needed to determine the relationship between the pollinizer and the phenolics accumulation pattern in the 'Porotan' pellicle.

\section{Acknowledgements}

This study was partly financially supported by
Research and Development Projects for Application in Promoting New Policy of Agriculture Forestry and Fisheries.

\section{Literature Cited}

Hara, H., T. Matsuda, T. Tsukihashi and T. Matsuda. 1995. Morphological studies on pellicle development and removal in chestnut. J. Japan. Soc. Hort. Sci. 64: 485-497 (In Japanese with English abstract).

Hirabayashi, T., K. Kotobuki, T. Saito, Y. Sawamura, O. Terai, M. Shoda, K. Abe, Y. Sato, N. Takada, A. Sato, T. Nishihata, Y. Kashimura, K. Suzuki, T. Kihara, M. Uchida, T. Kosono and H. Fukuda. 2007. 'Porotan', a new chestnut cultivar. Hort. Res. (Japan) 6 (Suppl. 1): 71 (In Japanese).

Kikuchi, A. 1948. Kuri. p. 231-245. Kajuengeigaku Joukan (In Japanese). Yokendo, Tokyo.

Kotobuki, K. 1994. Chestnut. p. 53-55. In: K. Konishi, S. Iwahori, H. Kitagawa and T. Yakuwa (eds.). Horticulture in Japan. Asakura Shoten, Tokyo.

Kotobuki, K. 1996. Rihei Guri. p. 228-229. In: I. Kozaki, I. Ueno, S. Tsuchiya and I. Kajiura (eds.). The fruits in Japan. Yokendo, Tokyo.

Miller, G., D. D. Miller and R. A. Jaynes. 1996. Chestnuts. p. 99123. In: J. Janick and J. N. Moore (eds.). Fruit breeding vol. III Nuts. John Wiley \& Son, Inc., New York.

Ministry of Agriculture, Forestry and Fisheries. 2009. Sakkyou Chousa (Kaju). http://www.maff.go.jp/j/tokei/kouhyou/ sakumotu/sakkyou_kazyu/index.html\#r, April 7, 2010.

Nakabayashi, T. 1967. Tannin. p. 64-221. In: Nakabayashi, T., S. Kimura and H. Kato (eds.). Color and discoloration of food (In Japanese). Korin-shoin. Tokyo.

Osaki, M. and H. Sasou. 1942. Studies of removal of pellicles in Chinese chestnut. J. Japan. Soc. Hort. Sci. 13: 229-232 (In Japanese).

Shoda, M., N. Takada, T. Saito, Y. Sawamura and K. Kotobuki. 2006. A method for quickly removing pellicles from chestnuts by deep frying in cooking oil. Bull. Natl. Inst. Fruit Tree Sci. 5: 21-27 (In Japanese with English abstract).

Takada, N., Y. Sawamura, S. Nishio and T. Saito. 2009. Influence of pollen parents on removability of pellicle and fruit weight of chestnut cultivar 'Porotan'.2. Hort. Res. (Japan) 8 (Suppl. 1): 38 (In Japanese).

Tanaka, K. and K. Kotobuki. 1992a. Analysis of histological and chemical factors related to the ease of pellicle removal in Japanese chestnut. J. Japan. Soc. Hort. Sci. 61: 1-6 (In Japanese with English abstract).

Tanaka, K. and K. Kotobuki. 1992b. Comparative ease of pellicle removal among Japanese chestnut (Castanea crenata Sieb. et Zucc.) and Chinese chestnut (C.mollissima Blume) and their hybrids. J. Japan. Soc. Hort. Sci. 60: 811-819.

Tanaka, K. and K. Kotobuki. 1998a. Partial purification, estimated chemical structure, and the adhesive property of castahesion between the pellicle and kernel of chestnut. J. Japan. Soc. Hort. Sci. 67: 14-20.

Tanaka, K. and K. Kotobuki. 1998b. The role of phenolic substances in the adhesion between the pellicle and kernel of Japanese chestnut under experimental conditions. J. Japan. Soc. Hort. Sci. 67: 1-8.

Tanaka, K., K. Kotobuki and N. Kakiuchi. 1981. Numerization of peeling easiness and role of phenolic compounds of the pellicle in the adhesion between the pellicle and embryo in comparison of Japanese (Castanea crenata Sieb. et Zucc.) and Chinese (Castanea mollissima Blume) chestnuts. J. Japan. Soc. Hort. Sci. 50: 363-371. 